\title{
Cocaine exposure and mother-toddler social play
}

\author{
Susan Brunner Uhlhorn ${ }^{\mathrm{a}, *}$, Daniel S. Messinger ${ }^{\mathrm{c}}$, Charles R. Bauer ${ }^{\mathrm{b}}$ \\ ${ }^{a}$ University of Miami, School of Medicine, Department of Pediatrics, P.O. Box 016820 (D-820), Miami, FL 33133, USA \\ ${ }^{\mathrm{b}}$ School of Medicine, University of Miami, Miami, FL 33101, USA \\ ${ }^{c}$ Department of Psychology, University of Miami, Miami, FL, USA
}

Received 1 January 2004; received in revised form 18 October 2004; accepted 2 November 2004

\begin{abstract}
This study compared the play interactions of 18-month-old cocaine-exposed toddlers and their mothers $(n=48)$ to non-cocaine-exposed comparison toddlers and their mothers $(n=77)$. Coders blind to drug-exposure status reliably coded the interactions for maternal directiveness, positivity, and sensitivity; child social initiative and positivity; and dyadic responsiveness. There were no cocaine exposure group differences on any of the measures, with or without statistical controls for birth weight, SES, maternal age, and prenatal exposure to alcohol, marijuana, and cigarettes. Irrespective of cocaine exposure, low birth weight was associated with fewer maternal positive vocalizations and lower levels of maternal sensitivity. In higher SES dyads, children were more likely to respond to mother requests. The absence of cocaine exposure differences in social interactive behaviors during mother-child play in a relatively large sample of mothers and their children, is discussed with respect to the existing literature.

(C) 2004 Elsevier Inc. All rights reserved.
\end{abstract}

Keywords: Mother-child interaction; Play; Cocaine; Prenatal drug exposure

Since the first studies were published in the mid 1980's, research into the effects of prenatal cocaine exposure has revealed a mixed pattern of effects. The behavioral effects of cocaine appear to be subtle rather than global, and may not be evident in measures of children's general level of functioning (Frank, Augustyn, Grant Knight, Pell, \& Zuckerman, 2001; Lester \& Tronick, 1994; Lester, LaGasse, \& Seifer, 1998; Lester et al., 2002). Studies examining social-emotional regulatory abilities have been somewhat

\footnotetext{
* Corresponding author. Tel.: +1 305243 5847; fax: +1 3052433312.

E-mail address: suhlhorn2@med.miami.edu (S.B. Uhlhorn).
} 
more revealing of drug exposure effects, but have not focused sufficiently on the interactive environment (Beeghly \& Tronick, 1994).

There is evidence of cocaine exposure deficits in emotional functioning and regulation. Studies have found exposed infants to show deficits in alertness and arousal, as well as emotional expression (Alessandri, Sullivan, Imaizumi, \& Lewis, 1993; Das Eiden, Lewis, Croff, \& Young, 2002; Mayes, Bornstein, Chawarska, Haynes, \& Granger, 1996; Mayes, Feldman, \& Granger, 1997; Roumell, Abramson, Delaney, \& Willey, 1997), but there has been relatively little research on this issue after 1 year of age. There also has not been adequate research examining how possible exposure deficits might be expressed in social interaction. Given the dynamic nature of social interaction, an assessment of both interactive partners is warranted. The current study approaches mother-child play as a milieu for dyadic social interaction, focusing on interactive behaviors that have shown prominence in the literature and an ability to reveal meaningful variation in the interaction between at-risk dyads.

Mother's participation in play has been shown to positively influence the child's level of play (Fiese, 1990; O’Connell \& Bretherton, 1984; Slade, 1987). However, mother participation needs to become less directive after the first year, as children are able to take on a leading role and try out new skills (Tamis-LeMonda \& Bornstein, 1991). The persistence and prominence of directiveness may indicate a less optimal interactive pattern in the dyad.

There is some evidence that drug-using mothers show less emotional expression, and are less responsive and engaged with their infants (Burns, Chethik, Burns, \& Clark, 1991; Gottwald \& Thurman, 1994; LaGasse et al., 2003). In turn, this inattention can result in fewer dyadic reciprocal, cooperative interactions (Mayes et al., 1997). Yet other research groups have not found associations between cocaine exposure and maternal interaction in early infancy (Neuspiel, Hamel, Hochberg, Greene, \& Campbell, 1991) or at 1 year (Ukeje, Bendersky, \& Lewis, 2001). However, in one of the few studies beyond infancy, a large sample of cocaine exposed preschoolers and their mothers revealed a poorer quality of interaction than the non-exposed group (Johnson et al., 2002). There was more maternal intrusiveness, hostility, poor quality of instruction, and lower maternal confidence in cocaine exposed dyads. Moreover, recent results from the Maternal Lifestyle Study (Seifer et al., 2004) show a small association between combined cocaine and opiate exposure and attachment classification at 18 months, with drug exposed children more likely to show an ambivalent classification. Thus, there is support for drug exposure effects on dyadic interaction.

Maternal sensitivity and responsiveness have long been implicated as important variables in the mother-child relationship (Ainsworth, Bell, \& Stayton, 1974; Bornstein, 1989; Bernstein, Jeremy, \& Marcus, 1986; DeWolff \& van IJzendoorn, 1997). Maternal responsiveness has been associated with increased child competence in cognition and language, as well as decreased behavior problems (McGrath, Sullivan, \& Seifer, 1998; Moore, Saylor, \& Boyce, 1998; Wakschlag \& Hans, 1999). This has been demonstrated in both normative (e.g. Olson, Bates, \& Bayles, 1984; Tamis-LeMonda, Bornstein, \& Baumwell, 2001) and at-risk populations (Kelly, Morisset, Barnard, Hammond, \& Booth, 1996; McGrath et al., 1998), but has not been adequately explored in cocaine-exposed samples.

Research on drug-exposed children's social behavior has shown preschoolers to demonstrate less social initiative, and fewer positive social interactions at 8-10 months (Beckwith et al., 1994; Burns et al., 1991). Less dyadic enthusiasm overall in the interaction has also been reported (Burns, Chethik, Burns, \& Clark, 1997). These social behaviors may be particularly lacking in drug-exposed dyads.

Factors associated with cocaine exposure that can put the child at increased risk include low infant birth weight and low maternal socioeconomic status (Addis, Moretti, Syed, Einarson, \& Koren, 2001; Lutiger, Graham, Einarson, \& Koren, 1991). Low birth weight in itself is known to be a risk factor for 
poor child outcome, particularly when combined with other risk factors (e.g. Hack, Klein, \& Taylor, 1995; Hollomon, Dobbins, \& Scott, 1998). The majority of research on prenatal drug use has focused on women of low SES, who typically present with a range of adverse sociodemographic and lifestyle factors (Woods, Behnke, Eyler, Conlon, \& Wobie, 1995). Low maternal education level, an index of lower SES, has been associated with the increased risk of a variety of poor child outcome (e.g. McLoyd, 1998), including poor quality mother-child interaction (Spiker, Ferguson, \& Brooks-Gunn, 1993). As such, both SES and low birth weight are important variables in the assessment of cocaine-exposed dyads.

In summary, there are important features of a mother's interaction style that can impact the child. A pattern of interacting associated with poor child outcome in other populations of at-risk children has also emerged from research with cocaine-exposed samples. Previous research has supported the importance of mother directiveness, sensitivity, and positive affect in the interaction, as well as child social initiative and positivity, and dyadic responsiveness. We anticipated cocaine-exposed dyads would display a less optimal interaction as assessed by measures of these constructs. We also expected low socioeconomic status and low infant birth weight, risk factors often associated with cocaine exposure, to have a detrimental impact on the play interaction.

\section{Method}

\subsection{Participants}

The 125 participants in this study are part of the Miami sample $(N=234)$ of the four-site Maternal Lifestyle Study (MLS). The MLS is a longitudinal multi-site study investigating the effects of prenatal cocaine/opiate exposure on child outcome, conducted under the auspices of the NICHD Neonatal Research Network (Bauer et al., 2002; Lester et al., 2002). Subjects were matched on race, sex, and gestational age (see Lester et al., 2002; Messinger et al., 2004, for details). Of the 212 participants who came in for the 18-month visit, 156 completed the play assessment. The play assessment was excluded when the larger research protocol precluded completion of the play assessment, which was ancillary project. Completed assessments were excluded if the play partner was a non-biological mother, a biological mother who had only recently regained child custody, a user of opiates, or if the assessment had technical problems preventing coding $(n=31)$. The final sample of 125 participants were designated as cocaine exposed $(n=48)$ by either maternal self-report at delivery or a meconium toxicology screen positive for cocaine metabolites; non-exposure $(n=77)$ was determined by negative self-report of use and a negative meconium toxicology screen (Lester et al., 2001).

There were no significant group differences in education level, marital status, SES or race (Table 1). The majority of mothers in both groups were African-American, never married, with less than a high school education. Mean maternal age differed between the groups, with nearly $70 \%$ of the exposed group between 26 and 35 years, and over half of the comparison group between 18 and 25 years.

Socioeconomic status was indexed by the standard algorithm described by Hollingshead (1975), as modified for low-income caregivers (LaGasse et al., 1999). The child's primary caregiver provided this data at the 1-month clinic visit. There were no significant differences between the groups on this SES index. Data on the prenatal use of other drugs was collected postpartum at the time of initial subject recruitment. Use of alcohol, tobacco, and marijuana was present in both groups (see Table 2). There was significantly more prenatal use of alcohol, tobacco and marijuana in the cocaine-exposed group. 
Table 1

Maternal demographics

\begin{tabular}{|c|c|c|c|}
\hline Maternal demographics & Exposed $(\%)(n=48)$ & Comparison $(\%)(n=77)$ & $p$ \\
\hline \multicolumn{4}{|l|}{ Maternal age } \\
\hline $18-25$ & $8(16.7 \%)$ & $42(54.5 \%)$ & \multirow[t]{3}{*}{$0.000^{* *}$} \\
\hline $26-35$ & $33(68.8 \%)$ & $30(39 \%)$ & \\
\hline $36-49$ & $7(14.6 \%)$ & $5(6.5 \%)$ & \\
\hline \multicolumn{4}{|l|}{ Education } \\
\hline$<12$ years & $29(60.4 \%)$ & $36(46.8 \%)$ & \multirow[t]{3}{*}{ N.S. } \\
\hline 12 years & $15(31.3 \%)$ & $33(42.9 \%)$ & \\
\hline+12 years & $4(8.3 \%)$ & $8(10.4 \%)$ & \\
\hline \multicolumn{4}{|l|}{ Marital status } \\
\hline Married & $7(14.6 \%)$ & $20(26 \%)$ & \multirow[t]{3}{*}{ N.S. } \\
\hline Never married & $39(81.3 \%)$ & $55(71.4 \%)$ & \\
\hline Divorced/widowed & $2(4.2 \%)$ & $2(2.6 \%)$ & \\
\hline \multicolumn{4}{|l|}{ SES } \\
\hline Index of social prestige (S.D.) & $30.77(10.45)$ & $28.64(8.57)$ & N.S. \\
\hline \multicolumn{4}{|l|}{ Race } \\
\hline African-American & $35(72.9 \%)$ & $62(80.5 \%)$ & \multirow[t]{4}{*}{ N.S. } \\
\hline White & $5(10.4 \%)$ & $1(1.3 \%)$ & \\
\hline Hispanic & $7(14.6 \%)$ & $13(16.5 \%)$ & \\
\hline Other & $1(2.1 \%)$ & $1(1.3 \%)$ & \\
\hline
\end{tabular}

N.S.: not significant.

${ }^{* *} p<0.001$.

Table 2

Frequency of prenatal poly-drug use

\begin{tabular}{|c|c|c|c|}
\hline Poly-drug use & Exposed $(n=48)$ & Comparison $(n=77)$ & $p$ \\
\hline Tobacco use & & & $0.000^{* *}$ \\
\hline None & $11(23 \%)$ & $66(86 \%)$ & \\
\hline Some ( $<10$ cigarettes per day) & $22(46 \%)$ & $6(8 \%)$ & \\
\hline High ( $\geq 10$ cigarettes per day) & $15(31 \%)$ & $5(6 \%)$ & \\
\hline Alcohol use & & & $0.000^{* *}$ \\
\hline None & $14(29 \%)$ & $50(65 \%)$ & \\
\hline Some $(<0.5 \mathrm{oz}$ AA per day $)$ & $28(58 \%)$ & $25(32 \%)$ & \\
\hline High ( $\geq 0.5$ oz AA per day) & $6(13 \%)$ & $2(3 \%)$ & \\
\hline Marijuana use & & & $0.000^{* *}$ \\
\hline None & $29(60 \%)$ & $74(96 \%)$ & \\
\hline Some $(<0.5$ joints per day $)$ & $14(29 \%)$ & $3(4 \%)$ & \\
\hline High ( $\geq 0.5$ joints per day) & $5(10 \%)$ & 0 & \\
\hline
\end{tabular}

AA: absolute alcohol content; $0.5 \mathrm{oz}$. AA is equal to one standard drink.

** $p<0.001$. 
Table 3

Child medical characteristics

\begin{tabular}{llll}
\hline Child medical characteristics & Exposed $(\%)(n=48)$ & Comparison $(\%)(n=77)$ & $p$ \\
\hline G.A. (weeks) & & & N.S. \\
$24-27$ & $2(4.2 \%)$ & $4(6.3 \%)$ & \\
$28-32$ & $4(8.2 \%)$ & $4(5.2 \%)$ & \\
$33-37$ & $9(18.4 \%)$ & $15(18.8 \%)$ & \\
$38-42$ & $33(69.4 \%)$ & $54(68.8 \%)$ & N.S. \\
Low birth weight & $11(22.9 \%)$ & $21(27.3 \%)$ & N.S. \\
Mean B.W. (S.D.) & $2740.85 \mathrm{~g}(913.02)$ & $2863.26 \mathrm{~g}(906.57)$ & N.S. \\
Sex (\% male) & $27(56.3 \%)$ & $39(50.6 \%)$ & \\
\hline
\end{tabular}

G.A.: gestational age; low birth weight: <2500 g; N.S.: not significant

B.W.: birth weight.

There were no significant group differences on the infant medical variables (Table 3). The majority of subjects in both groups were born full term; approximately one quarter of each group was low birth weight $(<2500 \mathrm{~g})$.

\subsection{Procedure}

After consenting to the procedure, mothers engaged in a 10-min unstructured play session with their child. The mother was instructed to play with her child as she normally would at home, using a set of attractive, age appropriate toys. Examiners were masked to the dyad's drug exposure status. The interaction was videotaped through a one-way mirror for later coding.

\subsection{Measures}

The behaviors chosen to operationalize each measured construct were drawn from descriptions used in other studies, using behaviors that could be readily observed in a free-play situation (see Table 4). The constructs in the coding system are divided into those of the mother, child, and dyad. The maternal measures are directiveness, positivity, and sensitivity. The child measures are social initiative and positivity. The dyadic measure is responsiveness. The coding system uses frequency counts of specific behaviors included in each measure. Maternal sensitivity was assessed using Ainsworth's Sensitivity Rating Scale (Ainsworth et al., 1974), which rates maternal sensitivity on a scale from 1 (highly insensitive) to 9 (highly sensitive).

\subsection{Data coding}

Videotaped data was coded using a computer program for real-time frequency coding (Action Analysis Coding and Transcription, 1996). Reliability was assessed with intra-class correlations, indicating the proportion of total variance in coding due to the coder's agreements on differences between subjects for a given code. Using a sample of $16 \%$ of the assessments $(n=20)$, coders' intra-class coefficients ranged from 0.75 (maternal requests fulfilled) to 0.96 (maternal requests) in comparison with the first 
Table 4

Play measures

\begin{tabular}{|c|c|}
\hline Code & Index variable (intra-class correlations) \\
\hline \multicolumn{2}{|l|}{ Mother codes } \\
\hline Directiveness & Number of requests $(0.96)$ and toy offers made to the child $(0.85)$ \\
\hline Positivity & Number of smiles $(0.89)$ and positive vocalizations $(0.79)$ \\
\hline Sensitivity & $\begin{array}{l}\text { Ainsworth's Sensitivity Rating Scale (0.78); rates the mother's sensitivity on a scale of one to nine } \\
\text { highly sensitive }\end{array}$ \\
\hline \multicolumn{2}{|l|}{ Child codes } \\
\hline Social initiation & $\begin{array}{l}\text { Number of gazes to mother }(0.90) \text {, toy offers }(0.82) \text {, and coordinated joint attention episode initiations } \\
(0.77)\end{array}$ \\
\hline Positivity & Number of smiles $(0.91)$ \\
\hline \multicolumn{2}{|l|}{ Dyadic codes } \\
\hline Responsiveness & $\begin{array}{l}\text { Maternal responsiveness: proportion of child toy offers to which the } \\
\text { Mother complies }(0.89) \text {. Child responsiveness: proportion of maternal } \\
\text { requests }(0.75) \text { and toy offers }(0.93) \text { to which the child complies }\end{array}$ \\
\hline
\end{tabular}

Intra-class correlations in parentheses after variable.

author, indicating good reliability (see Table 4). Coders fluent in Spanish and Haitian-Creole coded dyads speaking those languages.

\subsection{Data analyses}

Data analyses consisted of three multivariate analyses of covariance (MANCOVA) for exposure group differences on maternal, child, and dyadic play variables, controlling for birth weight and SES. We also examined the empirical association of alcohol, marijuana, and tobacco exposure, and maternal age with the outcome variables. These variables were covaried only if they significantly differed between the groups or had a significant association with a given outcome. An alpha level of 0.05 was used for all statistical tests.

\section{Results}

The mean frequencies and standard deviations of the play variables are listed in Table 5. There was often a substantial degree of variability in the observed behaviors. The correlations are listed in Tables 6 and 7 , revealing a moderate degree of association between the child measures. Variables indexing alcohol, marijuana, and tobacco exposure, and maternal age showed no association with either infant, maternal, or dyadic outcome variables.

The MANCOVAs were conducted to evaluate the relationship between cocaine exposure and the play variables, while covarying SES and infant birth weight. The MANCOVAs did not reveal any exposure group differences in the mother, child, or dyadic variables; power to detect differences within this sample ranged from 0.18 to 0.37 . However, there was a significant main effect for infant birth weight on the maternal variables [Wilks' $\Lambda=0.864, F(1,124)=2.24, p<0.05, \eta_{\mathrm{p}}^{2}=0.12$, power $=0.83$ ], but not on the child or dyadic variables. Follow up analyses indicated that low birth weight was associated with 
Table 5

Mean frequencies and standard deviations of play interaction variables

\begin{tabular}{|c|c|c|c|c|c|}
\hline \multirow[t]{2}{*}{ Play interaction variables } & \multicolumn{2}{|c|}{ Exposed $(n=48)$} & \multicolumn{2}{|c|}{ Comparison $(n=77)$} & \multirow[t]{2}{*}{$p$} \\
\hline & $M$ & S.D. & $M$ & S.D. & \\
\hline \multicolumn{6}{|l|}{ Mother } \\
\hline Directiveness & & & & & N.S. \\
\hline Request & 40.40 & 27.67 & 35.71 & 25.67 & \\
\hline Offer toy & 11.60 & 7.90 & 12.61 & 7.59 & \\
\hline Positivity & & & & & N.S. \\
\hline Positive vocalization & 4.42 & 5.45 & 3.49 & 4.96 & \\
\hline Smile & 6.40 & 5.11 & 5.31 & 5.01 & \\
\hline Negative vocalization & 3.29 & 3.48 & 3.34 & 4.13 & \\
\hline Sensitivity rating (1-9) & 5.85 & 1.44 & 5.92 & 1.61 & N.S. \\
\hline \multicolumn{6}{|l|}{ Child } \\
\hline Social initiative & & & & & N.S. \\
\hline Gaze & 19.15 & 11.44 & 18.53 & 11.36 & \\
\hline Offer toy & 6.08 & 6.38 & 4.53 & 4.31 & \\
\hline Joint attention & 0.60 & 1.16 & 0.95 & 1.72 & \\
\hline Positivity & & & & & N.S. \\
\hline Smile & 3.75 & 3.85 & 3.79 & 4.01 & \\
\hline \multicolumn{6}{|l|}{ Dyad } \\
\hline Responsiveness & & & & & N.S. \\
\hline Maternal request fulfilled by child & $20 \%$ & 0.15 & $18 \%$ & 0.16 & \\
\hline Maternal offer fulfilled by child & $75 \%$ & 0.24 & $68 \%$ & 0.22 & \\
\hline Child offer fulfilled by mother & $73 \%$ & 0.03 & $71 \%$ & 0.38 & \\
\hline
\end{tabular}

None of the $p$ values were significant; NS: not significant.

Table 6

Correlations between mother and child variables

\begin{tabular}{|c|c|c|c|c|c|c|c|c|c|c|}
\hline \multirow[t]{2}{*}{ Child } & \multicolumn{6}{|l|}{ Child } & \multicolumn{4}{|l|}{ Mother } \\
\hline & Gaze & Smile & Toy offer & J.A. & Pos. voc. & Neg. voc. & Request & Offer & Smile & Sensitivity \\
\hline Gaze & - & & & & & & & & & \\
\hline Smile & $0.474^{* *}$ & - & & & & & & & & \\
\hline Toy offer & $421^{* *}$ & $0.313^{* *}$ & - & & & & & & & \\
\hline J.A. & $0.347^{* *}$ & 0.117 & $0.165^{*}$ & - & & & & & & \\
\hline \multicolumn{11}{|l|}{ Mother } \\
\hline Pos. voc. & 0.144 & 0.161 & $0.189^{*}$ & -0.007 & - & & & & & \\
\hline Neg. voc. & 0.044 & 0.029 & -0.070 & -0.119 & 0.055 & - & & & & \\
\hline Request & -0.016 & 0.058 & -0.060 & 0.010 & 0.085 & $0.212^{*}$ & - & & & \\
\hline Offer & 0.121 & 0.109 & $0.381^{* *}$ & $0.182^{* *}$ & -0.026 & 0.059 & 0.131 & - & & \\
\hline Smile & $0.196^{*}$ & $0.381^{* *}$ & 0.081 & 0.130 & $0.383^{* *}$ & 0.021 & 0.054 & -0.055 & - & \\
\hline Sensitivity & $0.186^{*}$ & 0.182 & 0.161 & $0.186^{*}$ & $0.239^{* * *}$ & $-0.200^{*}$ & $-0.183^{*}$ & 0.012 & $0.271^{* * *}$ & - \\
\hline
\end{tabular}

J.A.: joint attention; pos. voc.: positive vocalizations; neg. voc.: negative vocalizations.

${ }^{*} p<0.05$.

** $p<0.01$. 
Table 7

Correlations between mother, child, and dyadic variables

\begin{tabular}{|c|c|c|c|c|c|c|c|c|c|c|c|c|c|}
\hline \multirow[t]{2}{*}{ Dyad } & \multicolumn{6}{|l|}{ Child } & \multicolumn{4}{|l|}{ Mother } & \multicolumn{3}{|l|}{ Dyad } \\
\hline & Gaze & Smile & Toy offer & J.A. & Pos. voc. & Neg. voc. & Request & Offer & Smile & Senstv. & 1 & 2 & 3 \\
\hline 1 & 0.167 & 0.129 & $0.197^{*}$ & 0.141 & 0.086 & -0.108 & 0.021 & $-0.208^{*}$ & -0.003 & 0.134 & - & & \\
\hline 2 & 0.080 & 0.009 & 0.092 & -0.043 & 0.122 & -0.173 & $-0.319^{* *}$ & -0.079 & 0.136 & $0.215^{*}$ & 0.130 & - & \\
\hline 3 & 0.080 & 0.141 & $0.372^{* *}$ & 0.020 & 0.064 & 0.050 & -0.082 & 0.108 & 0.051 & 0.174 & 0.066 & 0.107 & - \\
\hline
\end{tabular}

Dyadic codes: (1) proportion of maternal requests fulfilled by child; (2) proportion of maternal offers fulfilled by child; (3) proportion of child offers fulfilled by mother. J.A.: joint attention; pos. voc.: positive vocalizations; neg. voc.: negative vocalizations; senstv.: sensitivity.

${ }^{*} p<0.05$.

** $p<0.01$.

fewer positive maternal vocalizations $\left[F(1,123)=4.09, p<0.05 ; \eta_{\mathrm{p}}^{2}=0.03\right.$, power $\left.=0.51\right]$ and lower sensitivity ratings $\left[F(1,123)=8.30, p<0.05 ; \eta_{\mathrm{p}}^{2}=0.06\right.$, power $\left.=0.81\right]$. There were a greater percentage of maternal requests fulfilled by the child in higher SES dyads $\left[F(1,123)=4.84, p<0.05 ; \eta_{\mathrm{p}}^{2}=0.04\right.$, power $=0.65]$.

\section{Discussion}

The purpose of this study was to explore the mother-child social play interactions of toddlers prenatally exposed to cocaine in a sample of 125 dyads. The study used play interaction variables that combined frequency counts and a rating scale to elucidate cocaine exposure group differences. This coding system did not reveal evidence of cocaine exposure effects on the mother, child, or dyadic features of play, although it was sensitive to differences due to birth weight and SES.

\subsection{Maternal findings}

More directiveness, less sensitivity and less positivity were expected in the exposed groups. The current study used a more objective measure of maternal directiveness (maternal requests) than that used previously with a smaller sample (Hagan \& Myers, 1997), but also found no exposure differences. Yet there may be aspects of the maternal request that are not being captured and that indicate important variance in the sample. We hypothesized that the sheer volume of requests would serve as an index of directiveness. Thus, the maternal requests code did not differentiate between outright commands, and requests that give the child more agency, such as those in the form of a question. Moreover, requests can either maintain the child's attention or redirect it. These aspects have been associated with both cognitive and social performance (Beckwith \& Rodning, 1996; Hart \& Risley,1995; Landry, Smith, Miller-Loncar, $\&$ Swank, 1997), and may be salient to maternal interactive styles in drug using samples.

Few studies have examined sensitivity in cocaine-using mothers; this is the first to have used Ainsworth's Sensitivity Scale (Ainsworth et al., 1974). Contrary to expectations, group differences were not found on this measure. Certainly a play situation allows for a restricted range of maternal behaviors to manifest. Perhaps sensitivity assessments done in the contexts of daily caregiving would be more revealing of any group differences. 
The interaction context may provide some explanation as to the overall lack of maternal findings. HoffGinsberg (1991) observed that a toy-play interaction produced the smallest group differences in maternal language. Their robust SES-related differences in maternal speech were most evident in routine caregiving activities, whereas the toy-play setting produced a predominance of directives from all mothers. Given that the drug-exposure effects between demographically similar groups are presumably less robust than SES effects, group differences in maternal verbal interaction style may be particularly elusive in a play setting.

\subsection{Child findings}

The current study's lack of social initiative differences are similar to past research using a rating scale to measure child social behavior (Burns et al., 1997). Research with a slightly older sample found that cocaine exposed 2 year olds showed less social initiative, as indexed by the frequency of acts involving the mother in play, such as offering a toy or vocalizing (Beckwith et al., 1994). Yet vocal bids to the mother were rarely observed in the current sample. Measures of social initiative that incorporate vocalizations may be more applicable to children 2 years of age or older. Our lack of group differences in child positive affect is consistent with findings from other large samples in the literature (Burns et al., 1997; Das Eiden et al., 2002; Ukeje et al., 2001).

\subsection{Dyadic findings}

Consistent with a smaller sample, we found no exposure group differences in dyadic responsiveness (Burns et al., 1997). The coding system utilized was similar to that used with normative samples (ClarkeStewart, 1973), but similar coding systems have not been used extensively with drug-exposed samples. Further exploration is needed into the quality and appropriateness of responsiveness, and the relationship between responsiveness and developmental outcome, in drug-exposed dyads.

\subsection{Low birth weight and SES findings}

Maternal sensitivity ratings were lower and maternal positive vocalizations were less frequent with low birth weight children. The correlation between sensitivity and positive vocalizations $(r=0.24)$ suggests that the constructs are not independent. It has been proposed that low birth weight infants have a need for specialized parenting styles to facilitate their development (Greenberg \& Crnic, 1988). Thus, mothers may use compensatory measures, such as increased directiveness, in an attempt to engage their child (McGrath et al., 1998). We did not find differences in directiveness by birth weight groups. But perhaps the less frequent positive vocalizations and reduced sensitivity reflects a form of altered interaction style in the low birth weight dyads.

In summary, the current study of 18 month olds interaction with their mothers parallels similar studies in finding little evidence of cocaine effects on child, mother, or dyadic behavior. These null findings may be function of the assessment itself; the play interaction may not have elicited the behaviors of interest. Conversely, the high levels of risk factors present in both groups may have not allowed group differences to manifest. Both groups had high proportions of low birth weight infants and mothers of low socioeconomic status, and both of these factors negatively influenced dyadic interaction. Thus, it was within the context of high but not uniform risk status, that subtle cocaine exposure effects were not detected. 


\section{Acknowledgements}

This study was supported by the National Institute of Child Health and Human Development through cooperative agreement (3 U10 HD021397-17S1) as well as intra-agency agreements with the National Institute on Drug Abuse (NIDA), Administration on Children, Youth, and Families (ACYF) and The Center for Substance Abuse Treatment (CSAT). We would like to thank the families who took part in this research and Susan Gautier, Wendy Griffin, Mary Triolo, and Lisa Eisen for their assistance in data collection; and Genise Vertus for her assistance in data coding. Portions of these data were reported at the biennial meeting of the International Society on Infant Studies (Toronto, Canada, April 2002).

\section{References}

Action Analysis Coding and Transcription (version 1.0) [computer software] (1996). Miami, FL: Intelligent Hearing Systems. Addis, A., Moretti, M. E., Syed, F. A., Einarson, T. R., \& Koren, G. (2001). Fetal effects of cocaine: an updated meta-analysis. Reproductive Toxicology, 15, 341-369.

Ainsworth, M. D. S., Bell, S. M., \& Stayton, D. J. (1974). Infant-mother attachment and social development: "Socialization" as a product of reciprocal responsiveness to signals. In M. P. M. Richards (Ed.), The integration of the child into a socialworld (pp. 99-135). Cambridge: Cambridge University Press.

Alessandri, S., Sullivan, M. W., Imaizumi, S., \& Lewis, M. (1993). Learning and emotional responsivity in cocaine-exposed infants. Developmental Psychology, 34, 989-997.

Bauer, C. R., Shankaran, S., Bada, H. S., Lester, B., Wright, L. L., Krause-Steinrauf, H., et al. (2002). The Maternal Lifestyle Study: Drug exposure during pregnancy and short-term maternal outcomes. American Journal of Obstetrics and Gynecology, 186, 487-495.

Beckwith, L., \& Rodning, C. (1996). Dyadic processes between mothers and preterm infants: Development at ages 2-5 years. Infant Mental Health Journal, 17, 322-333.

Beckwith, L., Rodning, C., Norris, D., Phillipsen, L., Khandabi, P., \& Howard, J. (1994). Spontaneous play in 2-year-olds born to substance-abusing mothers. Infant Mental Health Journal, 15, 189-201.

Beeghly, M., \& Tronick, E. Z. (1994). Effects of prenatal exposure to cocaine in early infancy: Toxic effects on the process of mutual regulation. Infant Mental Health Journal, 15, 158-175.

Bernstein, V., Jeremy, R. J., \& Marcus, J. (1986). Mother-infant interaction in multi-problem families: finding those at risk. Journal of the American Academy of Child Psychiatry, 25, 631-640.

Bornstein, M. H. (1989). In M. H. Bornstein (Ed.), Maternal responsiveness: Characteristics and consequences. New directions for child development. San Francisco: Jossey-Bass, no. 43.

Burns, K. A., Chethik, L., Burns, W. J., \& Clark, R. (1991). Dyadic disturbances in cocaine-abusing mothers and their infants. Journal of Clinical Psychology, 47, 316-319.

Burns, K. A., Chethik, L., Burns, W. J., \& Clark, R. (1997). The early relationship of drug abusing mothers and their infants: An assessment at 8-12 months of age. Journal of Clinical Psychology, 53, 279-287.

Clarke-Stewart, K. A. (1973). Interactions between mothers and their young children: characteristics and consequences. Monographs of the Society for Research in Child Development: 38. Chicago: University of Chicago Press, nos. 6-7 (serial no. 153).

Das Eiden, R., Lewis, A., Croff, S., \& Young, E. (2002). Maternal cocaine use and infant behavior. Infancy, 3, 77-96.

DeWolff, M. S., \& van IJzendoorn, M. H. (1997). Sensitivity and attachment: A meta-analysis on parental antecedents of infant attachment. Child Development, 68, 571-591.

Fiese, B. H. (1990). Playful relationships: A contextual analysis of mother-toddler interaction and symbolic play. Child Development, 64, 1648-1656.

Frank, D. A., Augustyn, M., Grant Knight, W., Pell, T., \& Zuckerman, B. (2001). Growth, development, and behavior in early childhood following prenatal cocaine exposure: A systematic review. Journal of the American Medical Association, 285, $1613-1625$. 
Gottwald, S. R., \& Thurman, S. K. (1994). The effects of prenatal cocaine exposure on mother-infant interaction and infant arousal in the newborn period. Topics in Early Childhood Special Education, 14, 217-231.

Greenberg, M. T., \& Crnic, K. A. (1988). Longitudinal predictors of developmental status and social interaction in premature and full-term infants at age two. Child Development, 59, 554-570.

Hack, M., Klein, N. K., \& Taylor, H. G. (1995). Long-term developmental outcomes of low birth weight infants. The Future of Children, 5, 176-196.

Hagan, J. C., \& Myers, B. J. (1997). Mother-toddler play interaction: A contrast of substance-exposed and nonexposed children. Infant Mental Health Journal, 18, 40-57.

Hart, B., \& Risley, T. R. (1995). Meaningful Differences in the Everyday Experience of Young American Children. Baltimore, MD: Paul H. Brookes Publishing.

Hoff-Ginsberg, E. (1991). Mother-child conversation in different social classes and communicative settings. Child Development, $62,782-796$.

Hollingshead, A. B. (1975). Four factor index of social status. New Haven, CT: Yale University Press.

Hollomon, H. A., Dobbins, D. R., \& Scott, K. G. (1998). The effects of biological and social risk factors on special education placement: Birth weight and maternal education as an example. Research in Developmental Disabilities, 19, $281-294$.

Johnson, A. L., Morrow, C. E., Accornero, V. H., Xue, L., Anthony, J. C., \& Bandstra, E. S. (2002). Maternal cocaine use: Estimated effects on mother-child play interactions in the preschool period. Developmental and Behavioral Pediatrics, 23, 191-202.

Kelly, J. F., Morisset, C. E., Barnard, K. E., Hammond, M. A., \& Booth, C. L. (1996). The influence of early mother-child interaction on preschool cognitive/linguistic outcomes in a high-social-risk group. Infant Mental Health Journal, 17, $310-321$.

LaGasse, L. L., Messinger, D. S., Lester, B. M., Seifer, R., Tronick, E. Z., Bauer, C. R., et al. (2003). Prenatal drug exposure and maternal and infant feeding behavior. Archives of Disease in Childhood, 88, F391-F399.

LaGasse, L., Seifer, R., Wright, L., Lester, B., Tronick, E., Bauer, C., et al. (1999). The Maternal Lifestyle Study (MLS): The caretaking environment of infants exposed to cocaine/opiates. Pediatric Research, 45, 247A.

Landry, S. H., Smith, K. E., Miller-Loncar, C. L., \& Swank, P. R. (1997). Predicting cognitive-language and social growth curves from early maternal behaviors in children of varying degrees of biological risk. Developmental Psychology, 33, $1040-1053$.

Lester, B. M., ElSohly, M., Wright, L., Smeriglio, V., Verter, J., Bauer, C., et al. (2001). The Maternal Lifestyles Study (MLS): Drug use by meconium toxicology and maternal self-report. Pediatrics, 107, 309-317.

Lester, B. M., Tronick, E. Z., LaGasse, L., Seifer, R., Bauer, C., Shankaran, S., et al. (2002). The Maternal Lifestyle Study (MLS): Effects of substance exposure during pregnancy on neurodevelopmental outcome in 1-month-old infants. Pediatrics, 110, 1182-1192.

Lester, B. M., LaGasse, L., \& Seifer, R. (1998). Cocaine exposure and children: The meaning of subtle effects. Science, 282, 633-634.

Lester, B. M., \& Tronick, E. Z. (1994). The effects of prenatal cocaine exposure on child outcome. Infant Mental Health Journal, 15, 107-120.

Lutiger, B., Graham, K., Einarson, T. R., \& Koren, G. (1991). Relationship between gestational cocaine use and pregnancy outcome: A meta-analysis. Teratology, 44, 405-414.

Mayes, L. C., Bornstein, M. H., Chawarska, K., Haynes, O. M., \& Granger, R. H. (1996). Impaired regulation of arousal in 3-month-old infants exposed prenatally to cocaine and other drugs. Development and Psychopathology, 8, $29-42$.

Mayes, L. C., Feldman, R., \& Granger, R. H. (1997). The effects of polydrug use with and without cocaine on mother infant interaction at 3 and 6 months. Infant Behavior and Development, 20, 489-502.

McGrath, M. M., Sullivan, M. C., \& Seifer, R. (1998). Maternal interaction patterns and preschool competence in high-risk children. Nursing Research, 47, 309-317.

McLoyd, V. C. (1998). Socioeconomic disadvantage and child development. American Psychologist, 53, $185-204$.

Messinger, D. S., Bauer, C. R., Das, A., Seifer, R., Lester, B. M., LaGasse, L. L., et al. (2004). The Maternal Lifestyle Study: Cognitive, motor, and behavioral outcomes of cocaine-exposed and opiate-exposed infants through 3 years of age. Pediatrics, $113,1677-1685$.

Moore, J. B., Saylor, C. F., \& Boyce, G. C. (1998). Parent-child interaction and developmental outcomes in medically fragile, high-risk children. Children's Health Care, 27, 97-112.

Neuspiel, D. R., Hamel, S. C., Hochberg, E., Greene, J., \& Campbell, D. (1991). Maternal cocaine use and infant behavior. Neurotoxicology and Teratology, 13, 229-233. 
O'Connell, B., \& Bretherton, I. (1984). Toddlers play alone and with the mother: The role of maternal guidance. In I. Bretherton (Ed.), Symbolic play: The development of social understanding (pp. 337-368). Orlando, FL: Academic Press.

Olson, S., Bates, J., \& Bayles, K. (1984). Mother-infant interaction and the development of individual differences in children's cognitive competence. Developmental Psychology, 20, 166-179.

Roumell, N., Abramson, L., Delaney, V., \& Willey, R. (1997). Facial expressivity to acute pain in cocaine-exposed infants. Infant Mental Health Journal, 18, 274-281.

Seifer, R. S., LaGasse, L. L., Lester, B. M., Bauer, C. R., Shankaran, S., Bada, H. S., et al. (2004). Attachment status in children prenatally exposed to cocaine and other substances. Child Development, 75, 850-868.

Slade, A. (1987). A longitudinal study of maternal involvement and symbolic play during the toddler period. Child Development, 64, 367-375.

Spiker, D., Ferguson, J., \& Brooks-Gunn, J. (1993). Enhancing maternal interactive behavior and child social competence in low birth weight, premature infants. Child Development, 64, 754-768.

Tamis-LeMonda, C. S., \& Bornstein, M. H. (1991). Individual variation, correspondence, stability, and change in mother and toddler play. Infant Behavior and Development, 14, 143-162.

Tamis-LeMonda, C. S., Bornstein, M. H., \& Baumwell, L. (2001). Maternal responsiveness and children's achievement of language milestones. Child Development, 72, 748-767.

Ukeje, I., Bendersky, M., \& Lewis, M. (2001). Mother-infant interaction at 12 months in prenatally cocaine-exposed children. American Journal of Drug and Alcohol Abuse, 27, 203-224.

Wakschlag, L. S., \& Hans, S. L. (1999). Relation of maternal responsiveness during infancy to the development of behavior problems in high-risk youths. Developmental Psychology, 35, 569-579.

Woods, N. S., Behnke, M., Eyler, F. D., Conlon, M., \& Wobie, K. (1995). Cocaine use among pregnant women: social obstetrical, and psychological issues. In M. Lewis \& M. Bendersky (Eds.), Mothers, babies, and cocaine: The role of toxins in development (pp. 305-332). Hillsdale, NJ: Lawrence Erlbaum Associates. 